\title{
A study on leaching behaviour of cement blocks used as matrix for fixation of Cs activity along with ferric
}

\author{
PUSHPA MUTHIAH, K S SESHADRI*, P K SINHA and K B LAL \\ Centralized Waste Management Facility, Bhabha Atomic Research Centre, Kalpakkam 603 102, India
}

MS received 3 July 2006

\begin{abstract}
Study on the cementation of the regenerated activity (from spent resin using ferric as regenerant) containing ferric in cement matrix showed that compressive strength and leaching behaviour are better when the ferric strength was $<5 \mathrm{~N}$. The diffusion coefficient of $\mathrm{Cs}$ from the cement matrix was found to be in the range $2.4 \times 10^{-5} \mathrm{~cm}^{2} /$ day and $5.9 \times 10^{-5} \mathrm{~cm}^{2} /$ day with ferric solutions of strength in the range $0.5-3 \mathrm{~N}$. When bentonite and vermiculite were included in the cement matrix, the diffusion coefficient of $\mathrm{Cs}$ was found to be in the range $6.2 \times 10^{-7} \mathrm{~cm}^{2} /$ day to $1.26 \times 10^{-5} \mathrm{~cm}^{2} /$ day with ferric strength in the same range.
\end{abstract}

Keywords. Spent resin; multi valent; column; diffusion.

\section{Introduction}

Ion exchange resins are also used in purification of heavy water in the moderator system, primary heat transport system and in fuel storage pond water. It is imperative to treat the spent resin so formed into innocuous form, highly inert towards exchange with any external radioactivity.

The spent resin is disposed off in the radioactivity disposal area without treatment or fixed in cement or thermosetting polymer (Plecas and Pavlovic 2003). The other alternative method, acid digestion, generates a new kind of waste solution and complicates the final disposal.

Also it involves handling of concentrated mineral acids and gases viz. NOX, $\mathrm{SO}_{2}$ etc (Miriam Myzes 1982). Wet oxidation did not completely oxidize organic carbon to carbon dioxide gas (Kubota 1983). Hence an attempt has been made to convert the spent resin into ferric form. Regeneration of spent resin into ferric form renders the handling of almost non-active resin easily which can be fixed in cement or polymer safely.

Not much literature is available on the regeneration of spent resin into ferric form but the feasibility and conditions of conversion of one form of resin into another form has been reported (Vogel 1975). Since the regenerated activity will be accompanied by the ferric used as regenerant, it is imperative to study the cementation of Cs activity along with ferric.

\section{Materials and methods}

$\mathrm{H}^{+}$form of cation exchanger of make, Tulsion-46, of average particle size, $0.05 \mathrm{~cm}$ and pore size, $500 \AA$ (macro

*Author for correspondence (ksseshu@igcar.gov.in) reticular) with $50 \%$ water content procured from $\mathrm{M} / \mathrm{s}$ Thermax India Ltd, Pune, India, was used for the experiment.

AR grade cesium chloride, ferric chloride, iron powder, sodium thiosulphate, calcium chloride etc all procured from $\mathrm{M} / \mathrm{s}$ Sarabhai M Chemicals, Baroda, India and radioactive cesium procured from the Bhabha Atomic Research Centre, Trombay, Mumbai, India, were used in the preparation of simulated spent resin.

Radioactive cesium was analysed by single channel analyser.

Peristaltic pump of make, Miclins pp-20, was used for controlling the flow rate of the solutions for exchange. The cured blocks were subjected to compressive strength using compressive tester of make, $500 \mathrm{KN}$ Microprocessor based compression testing machine, AIM-311 E, M/AIMIL LTD, India.

The exchanged cesium was estimated from the analysis of radioactive cesium.

\section{Experimental}

\subsection{Fixation of Cs activity in cement}

Since the eluted activity along with ferric would be fixed in cement, experiments on cementation of Cs activity with ferric of different strengths was done with and without vermiculite and bentonite.

\subsection{Study on stability of cement blocks}

In order to study the feasibility of formation of cement blocks of different $\mathrm{pH}$, slurries of cement with ferric solutions of different strengths were prepared by mixing 
$10 \mathrm{~g}$ of cement with $5 \mathrm{ml}$ of ferric solutions of strength $0.5 \mathrm{~N}, 1 \mathrm{~N}, 3 \mathrm{~N}, 5 \mathrm{~N}, 7 \mathrm{~N}, 9 \mathrm{~N}, 11 \mathrm{~N}$ etc. A blank experiment was conducted without ferric. Table 1 shows the $\mathrm{pH}$ and temperature rise of the slurry when mixed.

Table 1. $\mathrm{pH}$ of cement ferric solution slurry at different strengths of ferric.

\begin{tabular}{lccc}
\hline S1. no. & Strength of ferric $(\mathrm{N})$ & $\mathrm{pH}$ & Temperature $\left({ }^{\circ} \mathrm{C}\right)$ \\
\hline 1 & 0 & $12 \cdot 4$ & 34 \\
2 & $0 \cdot 5$ & $12 \cdot 08$ & 34 \\
3 & $1 \cdot 0$ & $9 \cdot 9$ & 36 \\
4 & $3 \cdot 0$ & $5 \cdot 6$ & 44 \\
5 & $5 \cdot 0$ & $4 \cdot 8$ & 47 \\
6 & $7 \cdot 0$ & $4 \cdot 1$ & 53 \\
7 & $9 \cdot 0$ & $3 \cdot 3$ & 58 \\
8 & $11 \cdot 0$ & $3 \cdot 1$ & 67 \\
\hline
\end{tabular}
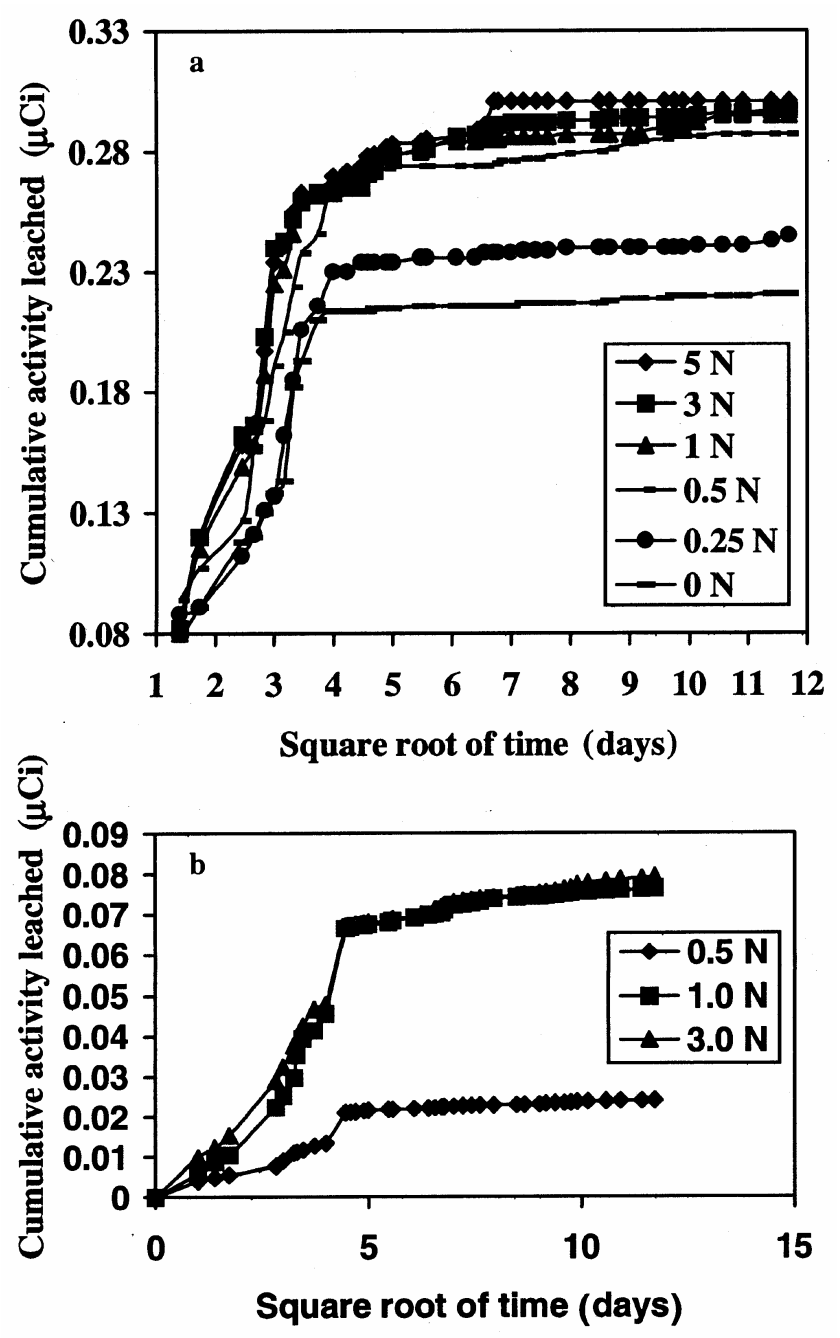

Figure 1. a. Leaching of $\mathrm{Cs}$ from cement matrix having ferric and $\mathbf{b}$. leaching of Cs activity from cement matrix having ferric, vermiculite and bentonite

\subsection{Optimization of period of curing of cement}

In order to confirm the results on the feasibility of formation of cement blocks and also to optimize the curing time to obtain cement blocks of maximum strength, $10 \mathrm{~g}$ of Portland cement was mixed with ferric solutions of strength, 1, 3, 5, 7, 9 and $11 \mathrm{~N}$. The slurries were molded into cement blocks of size, $5.5 \mathrm{~cm}$ dia and $2.5 \mathrm{~cm}$ height. A blank block without ferric was also prepared. The blocks were subjected to different curing periods, viz. 1, 2, 3, 4 and 5 weeks. Table 2 shows the compressive strength of cement blocks as a function of strength of ferric as well as curing time.

\subsection{Leaching of cement blocks containing Cs activity having ferric of different strengths with and without vermiculite and bentonite}

Cement blocks of size, $5.5 \times 2.5 \mathrm{~cm}$ height, were prepared by mixing $100 \mathrm{~g}$ of cement and $50 \mathrm{ml}$ of ferric solution of strength, $0.25 \mathrm{~N}, 0.5 \mathrm{~N}, 1 \mathrm{~N}, 3 \mathrm{~N}$ and $5 \mathrm{~N}$, containing $0.3 \mu \mathrm{Ci}$ of $\mathrm{Cs}$ with $5 \mathrm{~g}$ each of vermiculite and bentonite and without them. A blank block without ferric with Cs of activity $0 \cdot 3 \mu \mathrm{Ci}$ was also prepared. They were cured for 4 weeks. These blocks were kept in beakers containing $300 \mathrm{ml}$ of tap water. Replenishment of $300 \mathrm{ml}$ of tap water was done every time during sampling. Leaching of Cs from the cement blocks were computed by sampling the leachate every day for 1 week, on alternate days for 2 weeks, once in 15 days for one month and once in a month for nearly 4 months. The cumulative activity leached was calculated every time and it was plotted as a function of square root of time of leaching (figures $1 \mathrm{a}, \mathrm{b}$ ).

In order to calculate the diffusivity of $\mathrm{Cs}$ from the blocks, cumulative activity leached was plotted from 16 days onwards (figures $2 \mathrm{a}, \mathrm{b}$ ).

The diffusion coefficient calculated from this data was plotted as a function of strength of ferric used for making cement blocks (figures $3 \mathrm{a}, \mathrm{b}$ ).

The leach index as a function of strength of ferric ion strength is plotted for cement blocks with and without vermiculite and bentonite (figures $4 \mathrm{a}, \mathrm{b}$ ). The incremental leach rate was calculated at every instant of time and plotted as a function of time of leaching (figures $5 \mathrm{a}, \mathrm{b}$ ). The incremental leach rate at 16th day and at the 137th day was plotted as a function of strength of ferric used for making cement blocks (figures 6a, b). The percentage activity leached after 16 days and 137 days are shown in figures $7 \mathrm{a}$ and $\mathrm{b}$ from cement blocks without and with vermiculite, respectively.

\section{Results and discussion}

Chemical fixation of toxic and hazardous wastes using cement has been practised for many years. Portland cement 
Table 2. Compressive strength of cement blocks having different strengths of ferric.

\begin{tabular}{|c|c|c|c|c|c|c|}
\hline \multirow[b]{2}{*}{ S1. no. } & \multirow[b]{2}{*}{ Strength of ferric $(\mathrm{N})$} & \multicolumn{5}{|c|}{ Compressive strength $\left(\mathrm{kg} / \mathrm{cm}^{2}\right)$} \\
\hline & & I week & II weeks & III weeks & IV weeks & V weeks \\
\hline 1 & 0 & $105 \cdot 64$ & $154 \cdot 46$ & 272.73 & $275 \cdot 67$ & $276 \cdot 09$ \\
\hline 2 & $0 \cdot 5$ & $101 \cdot 85$ & 151.94 & $269 \cdot 78$ & $274 \cdot 41$ & $275 \cdot 67$ \\
\hline 3 & 1 & $98 \cdot 91$ & $147 \cdot 31$ & $244 \cdot 11$ & 271.46 & $272 \cdot 31$ \\
\hline 4 & 3 & 93.43 & $159 \cdot 93$ & $239 \cdot 90$ & $264 \cdot 31$ & $264 \cdot 73$ \\
\hline 5 & 5 & $77 \cdot 86$ & $88 \cdot 38$ & $114 \cdot 90$ & $113 \cdot 64$ & $114 \cdot 48$ \\
\hline 6 & 7 & $58 \cdot 92$ & $63 \cdot 13$ & $27 \cdot 36$ & $34 \cdot 10$ & 34.93 \\
\hline 7 & 9 & $56 \cdot 82$ & $58 \cdot 92$ & $26 \cdot 52$ & $31 \cdot 57$ & 31.99 \\
\hline 8 & 11 & $29 \cdot 46$ & $37 \cdot 88$ & $25 \cdot 25$ & $26 \cdot 09$ & $26 \cdot 94$ \\
\hline
\end{tabular}
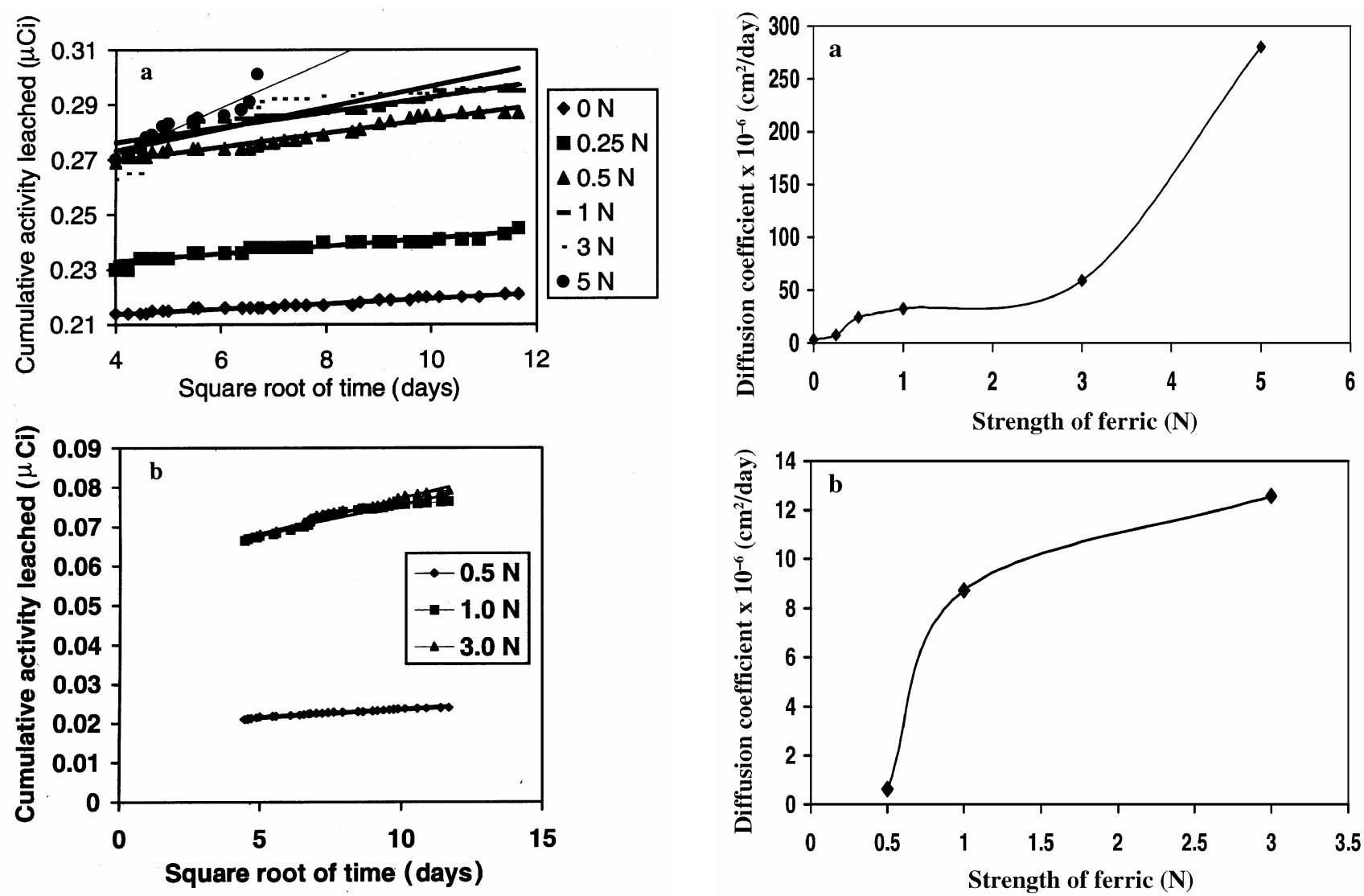

Figure 2. a. Leaching of Cs activity from cement matrix having ferric in the diffusion region and $\mathbf{b}$. leaching of Cs activity from cement matrix having ferric in presence of vermiculite and bentonite in the diffusion region.

is the most popular solidification agent for inorganic waste. Its high $\mathrm{pH}$ tends to keep the materials in the most insoluble form thus minimizing subsequent leaching. Portland cement is less useful with organics since some of them interfere with the overall setting and curing process (Plecas and Pavlovic 2004).

In column studies since 15 bed volumes elute all the activity from the spent resin containing $0.1 \mathrm{Ci} / \mathrm{m}^{3}, 15 \mathrm{~m}^{3}$ eluate will contain $0 \cdot 1 \mathrm{Ci}$, which corresponds to $0 \cdot 3 \mu \mathrm{Ci}$

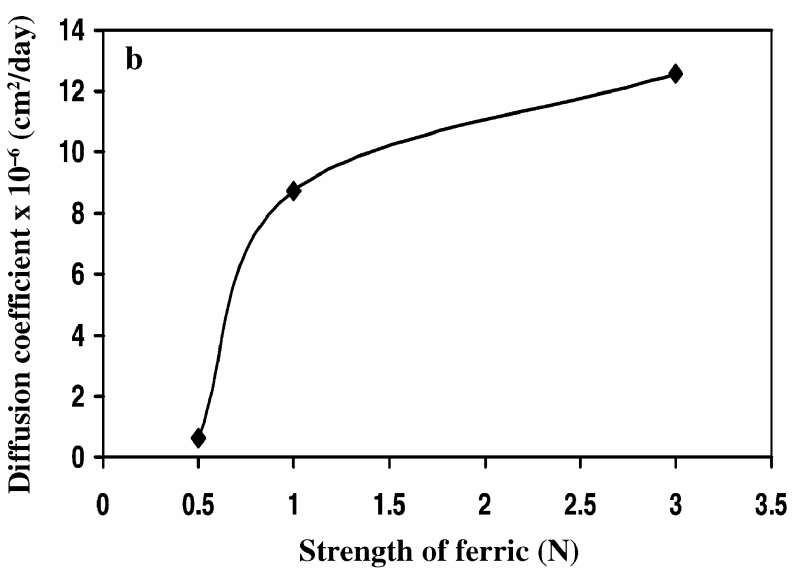

Figure 3. a. Diffusion coefficient of Cs from cement matrix having different strengths of ferric and $\mathbf{b}$. diffusion coefficient of $\mathrm{Cs}$ from cement matrix having ferric, vermiculite and bentonite.

per $50 \mathrm{ml}$ solution. Hence, for cementation studies, $50 \mathrm{ml}$ of $0.3 \mu \mathrm{Ci}$ Cs was taken with different strengths of ferric, viz. $0 \cdot 5-11 \mathrm{~N}$.

From table 1 it is observed that $\mathrm{pH}$ of the cement ferric solution slurry decreases with increase in ferric concentration. Ferric by hydrolysis gives rise to acidity which reduces the alkalinity of the cement slurry. Since the setting up of cement requires alkaline condition, the feasibility of cement blocks formation comes down with ferric. Also the 
reaction is exothermic with attendant increase in temperature as ferric strength increases. Therefore, there is water loss which hinders the setting process with ferric strength.

From table 2 it is inferred that at all strengths of ferric used for making the cement blocks the compressive strength is maximum at the 4 th week and hence the curing time is fixed as 4 weeks. Hence, blocks prepared were subjected to 4 weeks curing time before conducting leaching experiments with the blocks. Also the compressive strengths of the blocks decrease with ferric strength as expected from the decrease in the $\mathrm{pH}$.

From figures $1 \mathrm{a}, \mathrm{b}$, we observe that the cumulative activity leached increases at all strengths of ferric. But the cumulative activity leached has been found to be more with strength of ferric included in the blocks. Also from the blocks having bentonite and vermiculite (figure 1b), the leaching of Cs was found to be less at all strengths of ferric.

The washing activity taking place at the beginning of the cumulative activity leached was found to increase with time and after 16 days of leaching, the leaching was found to be lesser. For the purpose of calculation of diffusivity of $\mathrm{Cs}$ from the cement blocks, the cumulative activity leached after 16 days was considered.

From the plot of cumulative activity leached as a function of square root of time of leaching (figures $2 a, b$ ) in the
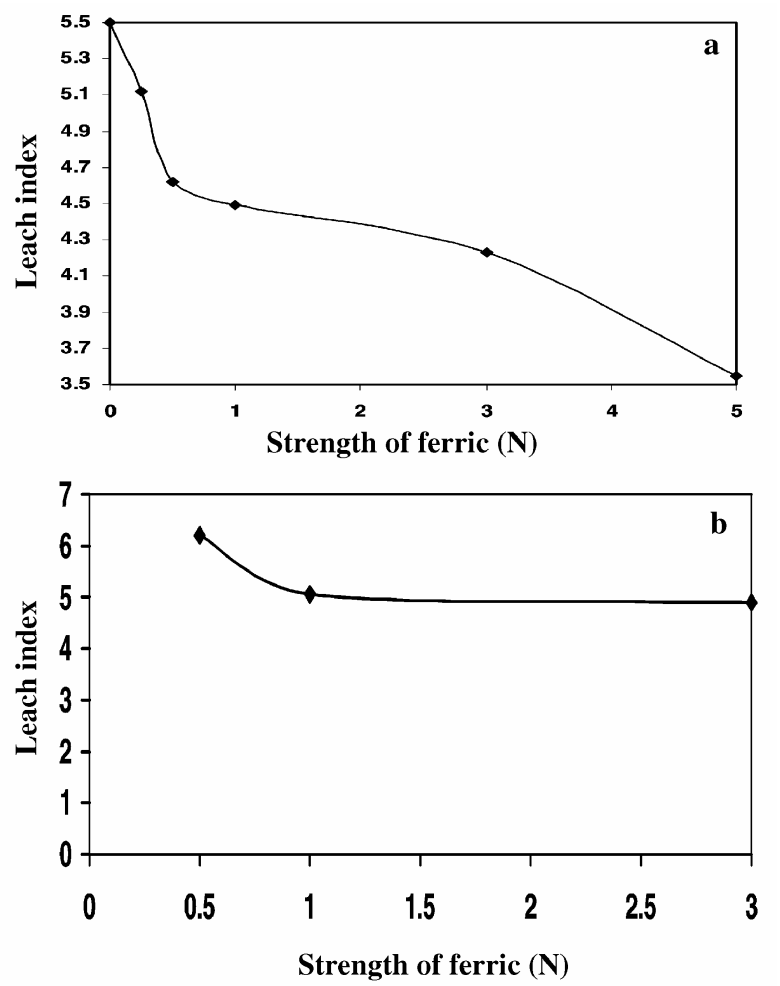

Figure 4. a. Variation of leach index of Cs from cement blocks with ferric as a function of strength of ferric and $\mathbf{b}$ variation of leach index of $\mathrm{Cs}$ from cement blocks having ferric in the presence of vermiculite and bentonite as a function of strength of ferric. diffusion region of leaching, slopes were computed and used for calculation of diffusion coefficient using the formula (Torsterfield and Heldin 1988)

$$
D=(\pi / 4)\left(m / a_{0}\right)^{2}(v / s)^{2},
$$

where $m$ is the slope of the plot between cumulative activity leached vs square root of time of leaching, $v$ and $s$ are the volume and surface area of the blocks, which are $59.42 \mathrm{~cm}^{3}$ and $90.75 \mathrm{~cm}^{2}$, respectively.

From figure $3 \mathrm{a}$ on the diffusion coefficient as a function of ferric ion strength, it is inferred that the diffusion coefficient increases with strength of ferric. Since the compressive strength of the blocks also comes down with strength of ferric, it is natural that Cs is held up weakly in the matrix and hence leaches more with more diffusivity. The diffusion coefficient of $\mathrm{Cs}$ from the blocks having
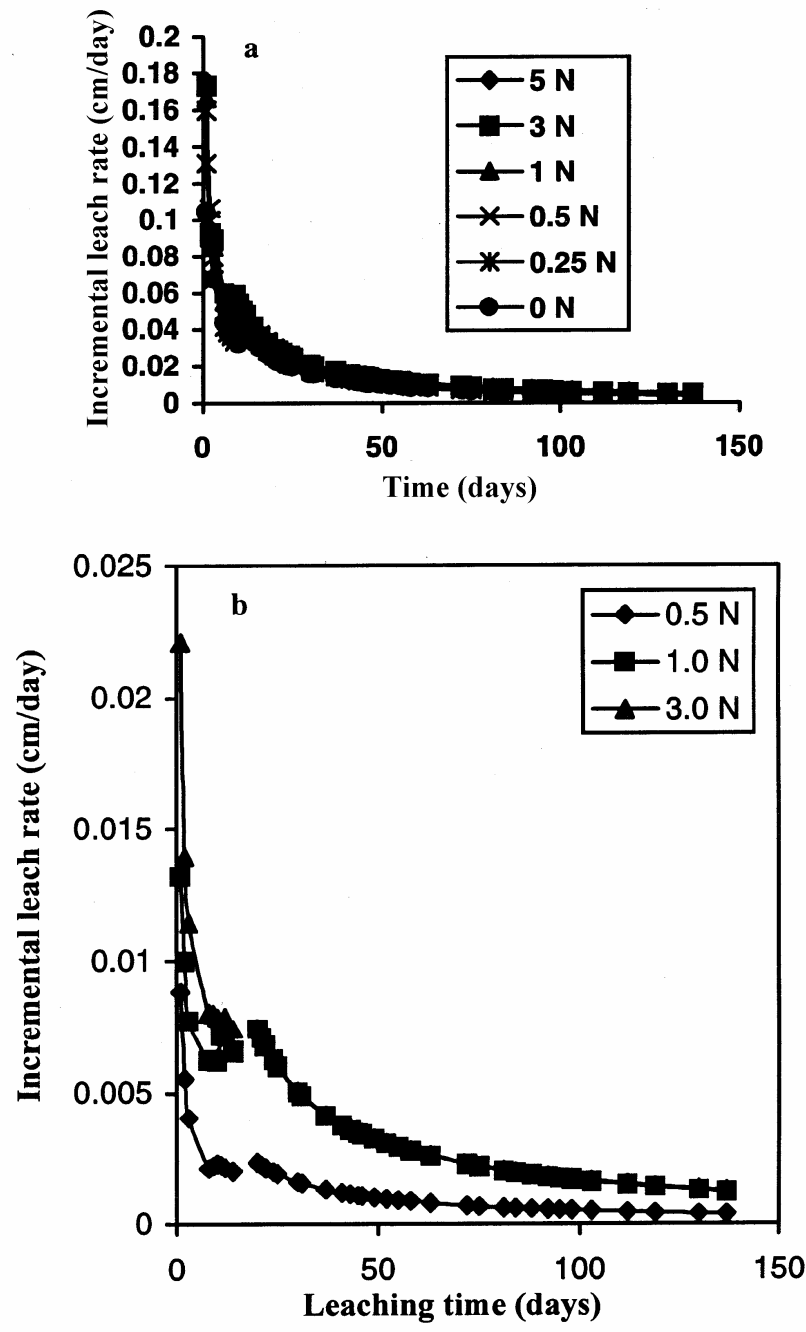

Figure 5. a. Incremental leach rate of $\mathrm{Cs}$ as a function of time from cement blocks containing different strengths of ferric and $\mathbf{b}$. incremental leach rate of Cs from cement blocks containing ferric in presence of bentonite and vermiculite as a function of time. 
bentonite and vermiculite (figure $3 b$ ) were found to be lesser at all ferric ion strengths.

It is generally assumed that cement leaching of $\mathrm{Cs}^{137}$ and other radionuclide can be reduced by adding minerals like bentonite, vermiculite and zeolite (Plecas et al 1991). Zeolite was excluded for economy and availability reasons. Bentonite and vermiculite were used in the solidification of radionucleides with cement. This is because vermiculite holds up the Cs strongly and bentonite does not allow water to percolate inside the matrix.

The leach index which is a direct measure of the extent of leaching of $\mathrm{Cs}$ from the cement blocks was computed from the formula

$$
\mathrm{LI}=\log (1 / D),
$$

where $D$ is the diffusion coefficient.
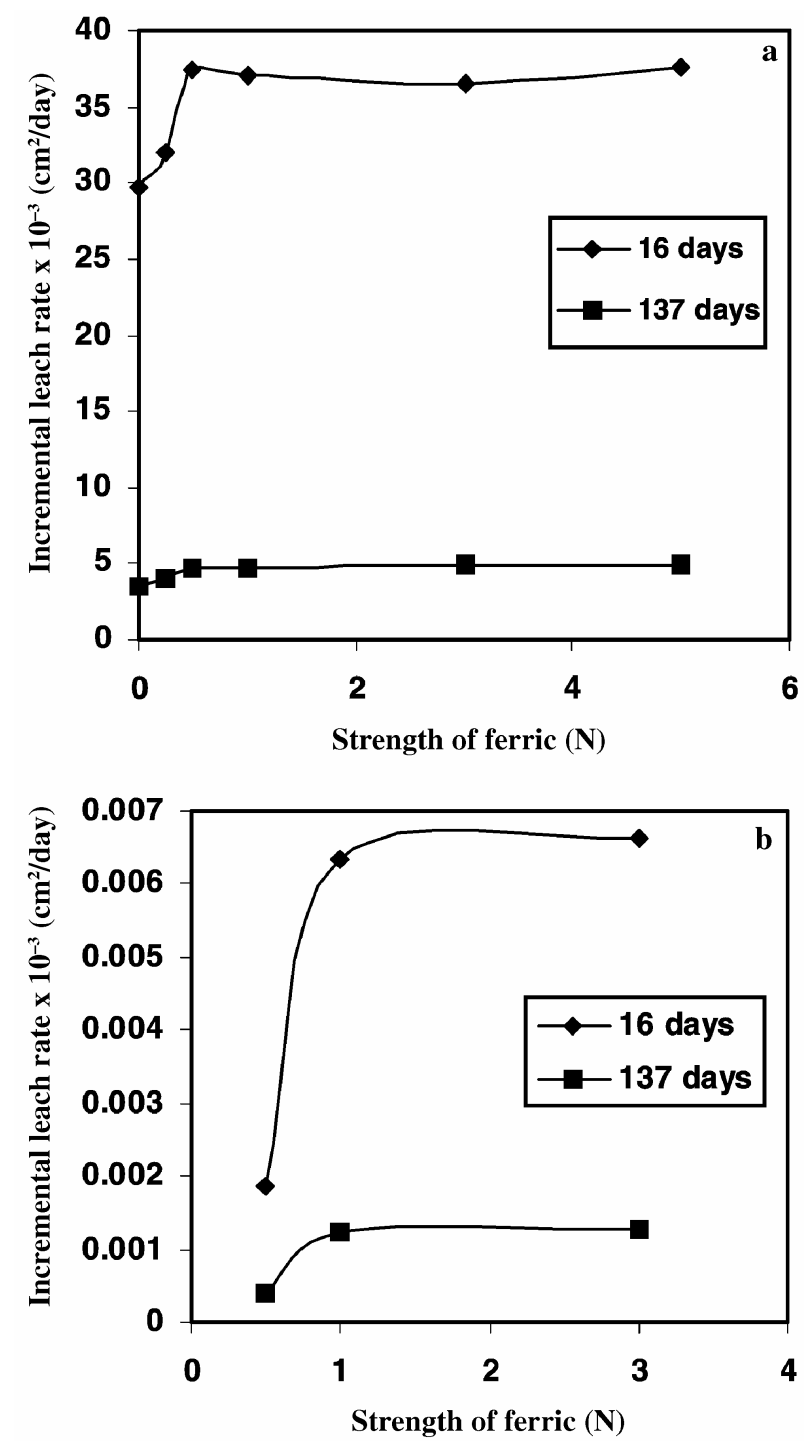

Figure 6. a. Incremental leach rate as a function of strength of ferric and $\mathbf{b}$. incremental leach rate from cement blocks having vermiculite and bentonite as a function of strength of ferric.
Higher the diffusion coefficient lower is the leach index. From figures $4 a$ and $b$, we observe that the leach index is more with blocks having vermiculite and bentonite.

The incremental leach rate is defined as

$$
\operatorname{ILR}=\sum a n / a_{0}(V / s)\left(1 /\left(\sum t_{\mathrm{n}}\right),\right.
$$

where $\sum a n / a_{0}$ is the fraction of activity leached and $\sum t_{\mathrm{n}}$ the cumulative period of leaching. The cumulative activity leached is plotted as a function of time (figures $5 \mathrm{a}$ and $\mathrm{b}$ ). The figures show that the incremental leach rate falls ex-
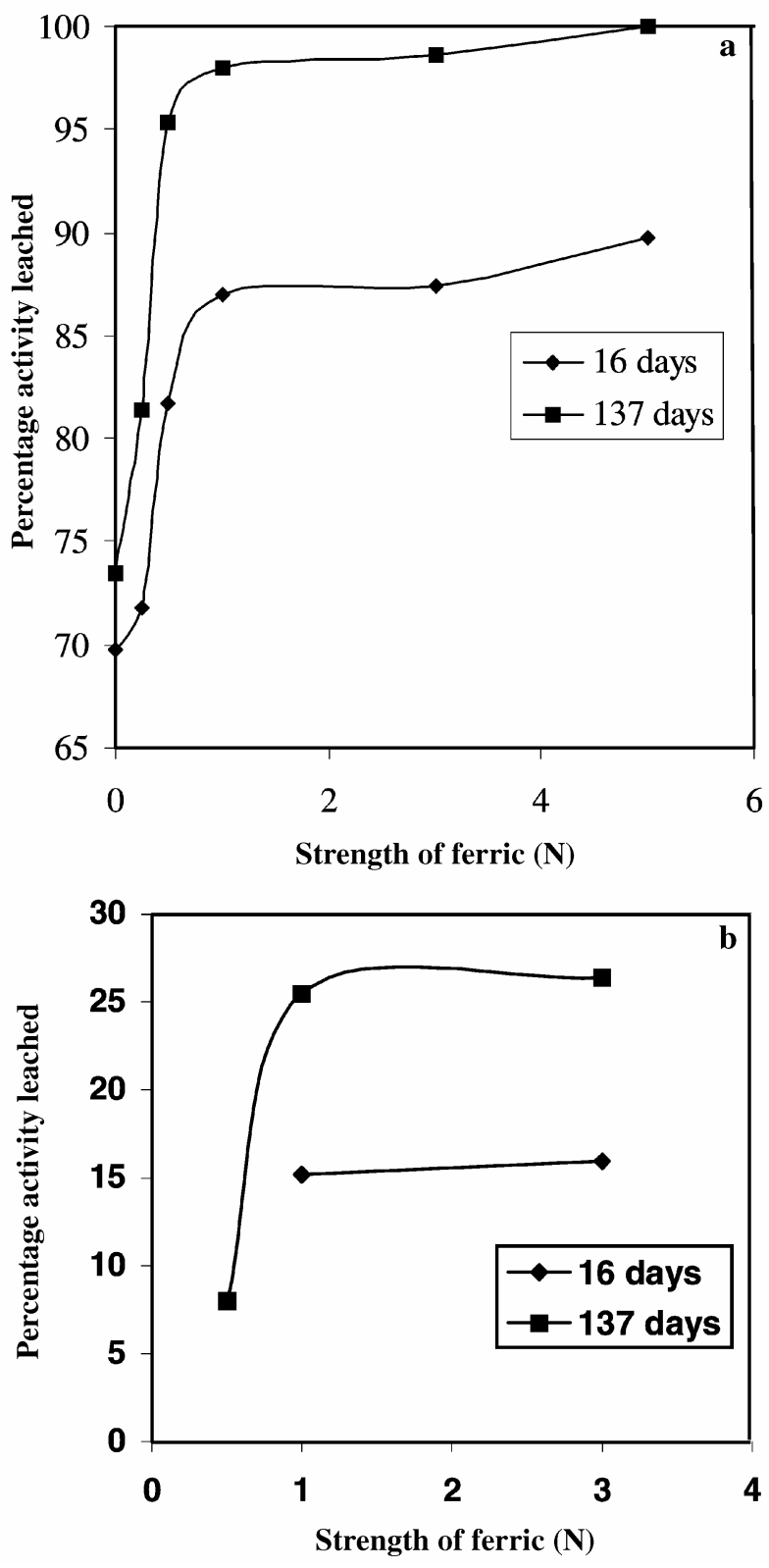

Figure 7. a. Percentage activity of $\mathrm{Cs}$ leached as a function of strength of ferric and $\mathbf{b}$. percentage activity of Cs leached as a function of ferric strength from cement matrix having vermiculite and bentonite. 
ponentially with period of leaching. It indicates that the rate of leaching comes down with time.

Figures $6 \mathrm{a}$ and $\mathrm{b}$ show the variation of incremental leach rate with time for the blocks with and without vermiculite and bentonite at 16th and 137th day of leaching which are the beginning of diffusion and end of our studies.

From figures $7 \mathrm{a}$ and $\mathrm{b}$, the \% activity leached was found to be 80 and 90 at 16th and 137th day for blocks without vermiculite and bentonite whereas for the blocks with vermiculite and bentonite the $\%$ activity was found to be $20-30 \%$ at 16 th and 137 th day, respectively. The results show that vermiculite and bentonite help in retaining the $\mathrm{Cs}$ in the cement blocks.

\section{Conclusions}

The regenerated activity along with ferric could be safely fixed in cement with different strengths of ferric. Vermiculite and bentonite help in making cement blocks of better leaching characteristics.

\section{Acknowledgements}

The authors express their thanks to Shri K B Dhayalan for his help in measuring the compressive strengths of the cement blocks, Shri S S Raj for her valuable discussions and Shri S Ramachandran and K Elumalai for their help in lab studies.

\section{References}

Kubota M 1983 J. Radio Anal. Chem. 78295

Miriam Mozes S 1982 Nucl. Technol. 59270

Plecas I, Peric A, Kostudinovic A and Drljaca J 1991 J. Radio Anal. Nucl. Chem. Letts 154121

Plecas I B and Pavlovic R V 2003 Bull. Mater. Sci. 26699

Plecas I B and Pavlovic R V 2004 Bull. Mater. Sci. 27175

Torsterfield B and Heldin G 1988 Scientific Basis for Nuclear Waste Management 127495

Vogel A I 1975 Textbook of quantitative inorganic analysis (London: Longman Group Limited) 3rd ed. Vol. 368, p. 372 